\title{
Reservoir Characteristics of Buried-hill Draping Zone in L Oilfield, Offshore China
}

\author{
Yujuan Liu ${ }^{1}$, Qianping Zhang ${ }^{1}$, Bin Zheng ${ }^{1}$, Jing Zhang ${ }^{1}$, Zhaozhao $\mathrm{Qu}^{1}$ \\ ${ }^{1}$ Bohai Oil Field Research Institute, Tianjin Branch of CNOOC Ltd., Tianjin 300459, China \\ Correspondence: Yujuan Liu, Bohai Oil Field Research Institute, Tianjin Branch of CNOOC Ltd., Tianjin, 300459, \\ China. Tel: 86-20-6650-0838. E-mail: liuyj7@cnooc.com.cn
}

Received: March 15, 2021

Accepted: April 29, $2021 \quad$ Online Published: May 28, 2021

doi:10.5539/esr.v10n2p33

URL: https://doi.org/10.5539/esr.v10n2p33

\begin{abstract}
The reservoir in different parts of buried-hill draping zone is often quite different, so it is of great significance to clarify the reservoir characteristics for exploration and development. Based on core, well logging, seismic data and production data, reservoir characteristics of oil layer II in the lower second member of Dongying Formation of L oilfield, Bohai Bay Basin, offshore eastern China are systematically studied. Analyses of seismic facies, well-seismic combination, paleogeomorphology, and sedimentary characteristics are carried out. Sediment source supply, lake level and buried hill basement geomorphology all contribute to reservoir quality. The research suggests that the different parts of buried-hill draping zone can be divided into four types. Reservoir thickness and physical properties vary. The area where the provenance direction is consistent with the ancient valley direction is a favorable location for the development of high-quality reservoirs. Under the guidance of the results, oilfield production practices in L oilfield offshore China are successful. Knowledge gained from study of L oilfield has application to the development of other similar fields.
\end{abstract}

Keywords: Bohai Bay Basin, buried-hill draping zone, paleogeomorphology, sedimentary facies, reservoir quality

\section{Introduction}

In recent years, oil and gas fields of commercial value have been found in buried hills and overlying strata in various oil-bearing basins in China (Jin et al., 2019; Tong et al., 2017; Cui et al., 2018; Zhao et al., 2010; Liu et al., 2014; Dong et al., 2015). The structure, reservoir characteristics and reservoir-forming mechanics of such buried hills and their overlying strata have become a research hotspot (Zhao et al., 2010; Wang et al., 2017; Luo et al., 2008; Ma, 2004). As overlying structures often have good hydrocarbon accumulation conditions, scholars have carried out studies on sedimentary reservoirs from the aspects of tectonic evolution of buried hill basement, paleogeomorphology control of sedimentation, and changes of base level cycle (Fu et al., 2016; Sun et al., 2008; Dong et al., 2016; Guo et al., 2015; Qiao et al., 2008). Bohai L oilfield is a faulted semi-anticline structure developed in the background of buried hills. Due to the lack of drilling data and low resolution of seismic data, there is a lack of systematic research on reservoir characteristics of the strata overlying the buried hill, also known as the buried-hill draping zone. Therefore, the reserves of Dongying braided-river delta sandstones in the buried-hill draping zone remain untapped in recent years. In order to guide the efficient utilization of the reserves in the buried-hill draping zone of Bohai L oilfield, it is necessary to combine the existing data to study the sedimentary reservoir, establish the sedimentary evolution model and make a fine prediction of the reservoir. Based on the sedimentary characteristics of oil layer II in the lower second member of Dongying Formation of Bohai L oilfield, this paper analyzes the sedimentary evolution through fine paleogeomorphology analysis and guides the efficient exploration of untapped areas.

\section{Geological Setting}

Bohai L oilfield is located in the middle part of Liaoxi low uplift, liaodong Bay, Bohai Sea. In the northwest, it is bounded by Liaoxi No. 1 fault, and in the southeast, it is adjacent to Liaozhong Depression. It is a faulted semi-anticlinal structure developed on the background of buried hills (Figure 1). The Quaternary Pingyuan Formation, Neogene Minghuazheng Formation, Guantao Formation, Paleogene Dongying Formation and Paleozoic strata are developed from top to bottom, among which the lower second member of Dongying Formation is the main oil-bearing strata. During the deposit period of the lower second member of Dongying Formation, the regional basin area as a whole was in a rifting stage. The lake level was rising and the basin area was in an overall rising datum cycle stage. Close to the edge of the basin, a braided river delta front was overall deposited in the study area under the control of a northeast source. Affected by the buried basement and the change of lake level, formation and reservoir thickness 
change greatly. According to the vertical reservoir characteristics and oil-gas-water system, the lower second member of Dongying Formation can be divided into four oil groups. Oil group II is the main oil group and is further subdivided into four small layers (Zhang et al., 2020).
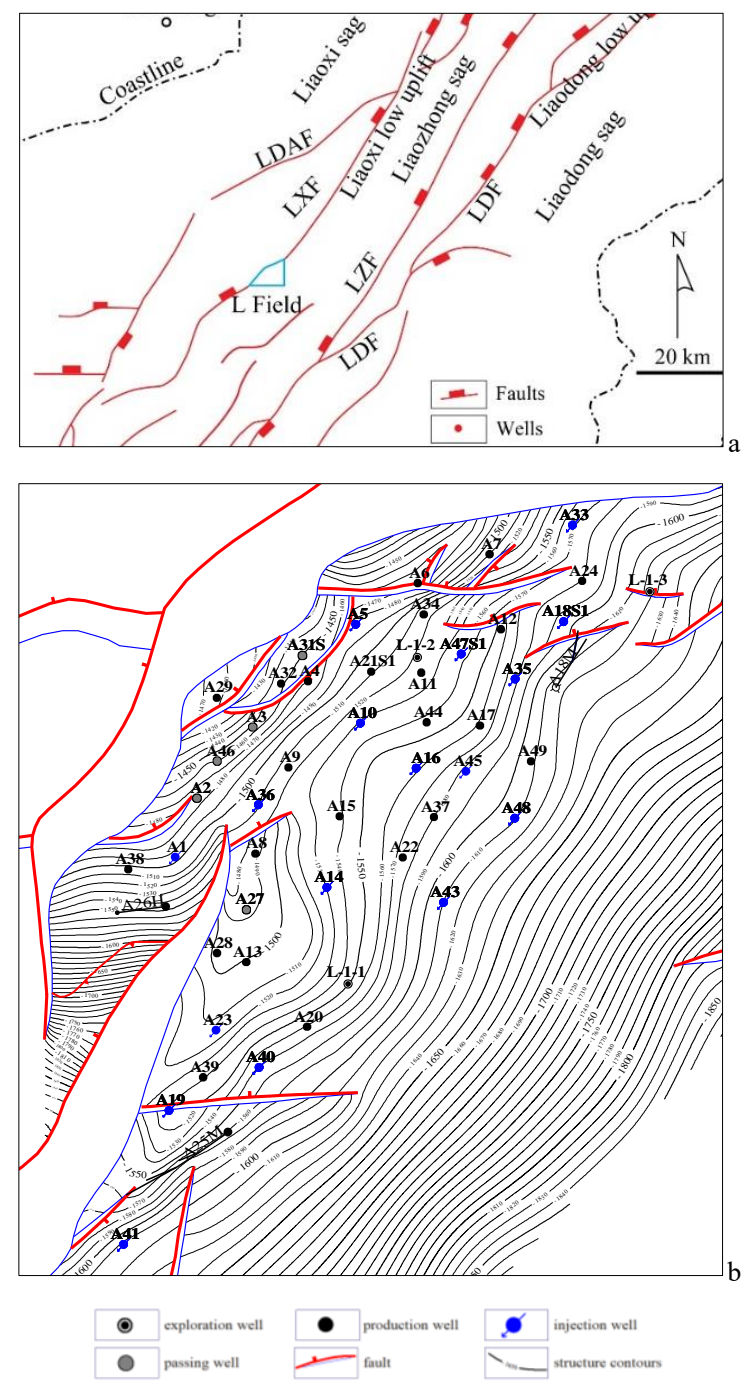

Figure 1. (a) Simplified structural map of L oilfield. The filed is marked with a blue frame. LXF indicate Liaoxi No.1 fault. (b) Location of wells included in this study. The location of exploratory wells is shown encircled.

\section{Fine Strata Division}

According to logging curves including spontaneous potential, natural gamma, deep and shallow lateral resistivity, density, and neutron, and combined with the characteristics of vertical cycle development and lateral changes of sand and mudstone, the strata is divided into single sand layers or composite sand bodies as basic units. Oil group II is divided into four small layers. In the buried-hill draping zone, the first small layer of oil group II is relatively stable and is developed in the overall region. The second and third small layers as a whole lie on the buried hill and the thickness and structure of strata vary. In addition, within well block L-1-1, the second and third small layers did not deposit. Under the influence of topography and ancient lake level, the thickness of the fourth small layer is overall smaller and in most regions, reaches zero (Figure 2). 


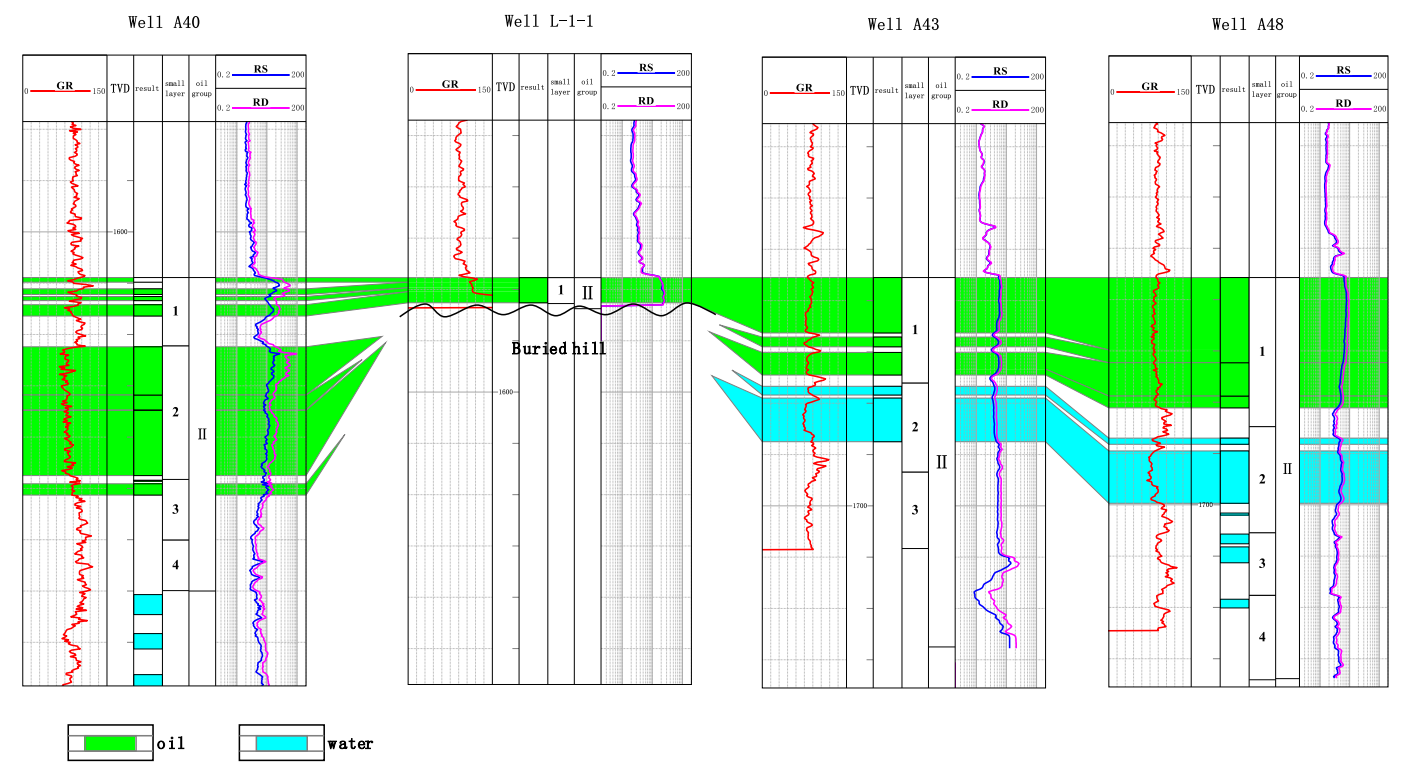

Figure 2. Fine layer division and correlation of oil group II of the lower second member of Dongying Formation in Bohai L oilfield. Well locations are shown in Figure 1b.

\section{Sedimentary Characteristics}

Based on analysis of regional sedimentary background, core, laboratory analysis, well logging data and seismic data, it is concluded that a braided river delta front, mainly including underwater distributary channel, channel edge, channel mouth bar, interdistributary bay and sheet sand deposition, is developed in the lower second member of Dongying Formation of the research area.

The underwater distributary channel deposits in the study area are mainly medium and fine gray sandstones with conglomerates locally present, and the natural gamma ray curves are usually bell-shaped and box-shaped, reflecting strong hydrodynamic characteristics. Due to the influence of the buried hill paleostructure, the hydrodynamic force towards the edge of the watercourse is weakened and the deposition is dominated by suspended deposition, thus the underwater distributary channel edge deposition is developed. The stratum of channel edge shows the mutual development between sand and mud and the natural gamma curve is usually jugged bell-shaped. The mouth bar deposits are mainly medium and fine sandstones and siltstones are mostly seen at the bottom, reflecting a coarsening-upward rhythm as a whole. The gamma curve is mainly in the shape of high amplitude finger and funnel. The sheet sand depositions are composed of interbedded siltstones and argillaceous siltstones, and are mostly separated vertically by lacustrine gray mudstones, showing the characteristics of interbedded sandstones and mudstones. The logging curves are usually finger-shaped with a medium amplitude. The interdistributary bay is mainly composed of mudstones with silty mudstones also visible. The color is mainly gray and gray-white, and carbon chips are present locally.

\section{Sedimentary Distribution and Evolution}

\subsection{Palaeogeomorphic Analysis}

The ancient landform in a certain extent controls the formation of sequence as well as the type and distribution of the sedimentary system (Dong et al., 2016; Gao et al., 2015). Thus, it is possible to reshape the paleo-provenance system, define the provenance, transport channels and relative distribution of different sedimentary microfacies, and finally predict sedimentary evolution and high-quality reservoir distribution through palaeogeomorphic analysis (Zhao et al., 2017; Lv et al., 2018; Ren et al., 2016; Yan et al., 2016; Shen et al., 2018).

Although the study area as a whole was a fault depression during the deposition of the second member of Dongying Formation, water area in the lake basin was relatively large and regional paleo-water-depth change was small. Thus, the influence of tectonic activity on deposition was weak. The strata thickness of oil group II is thick, so compaction restoration has less effect on the research of geomorphology and it is possible to restore paleogeomorphology through the method of layer flattening. Based on seismic data integrated with well data, the top of oil group II is flattened. And the paleogeomorphology during the deposition of oil group II of the lower second member of Dongying Formation is recovered by correction of drilling thickness (Figure 3). In general, the paleogeomorphology of the northwest of the 
study area is uneven. Ancient valleys develop at paleogeomorphologic low and can act as sediment channels. Part of the formation was not deposited at paleogeomorphologic high. Slopes with a southwest-northeast tendency characterize the paleogeomorphology of the southwest of the study area.

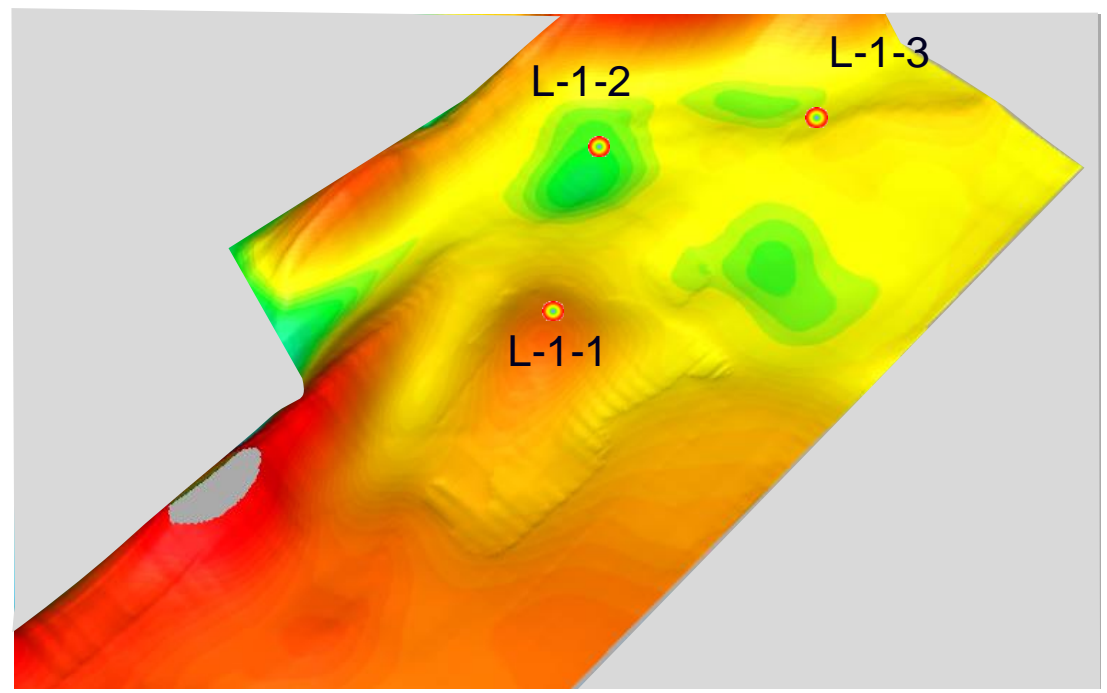

Figure 3. Paleogeomorphology of oil group II of the lower second member of Dongying Formation. The three exploratory wells are shown in Figure 1b.

\subsection{Seismic Facies Analysis}

Under the guidance of regional sedimentary model, combined with understanding of the constant rise of regional lake flood base level, seismic sedimentology is used to study reservoir sedimentology. Seismic facies analysis shows that seismic facies in the study area can be divided into valley filling facies (Figure 4a), onlap facies (Figure 4b) and parallel facies (Figure 4b). In combination with geomorphology characteristics, clear filling sedimentation can be seen inside the valleys in vertical source direction. With the continuous rising of lake level, sedimentary scope expands unceasingly and sediments overlap on the buried hill, forming onlap seismic facies. In addition, with the further increase of lake level, sediments develop overall during the deposition of the first small layer, forming parallel seismic facies. This is similar to drilling characteristics (Figure 5). In the early deposition stage, the main deposits near the buried hill were crevasse splay and sheet sand deposits which were far from the provenance. Meanwhile, under the influence of the early buried hill, the buried hill slump deposits were locally developed. With the rise of lake level, clastic rock deposits overlapped continuously over the buried hill until successive distribution in the study area.

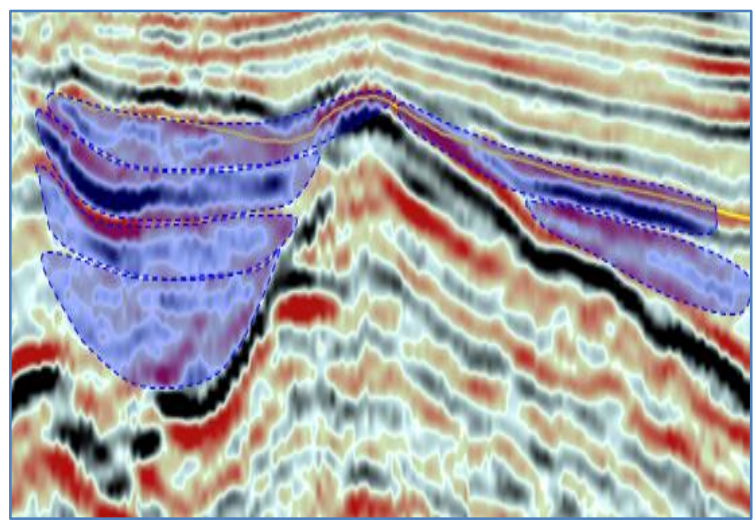

(a) seismic facies in a vertical source direction

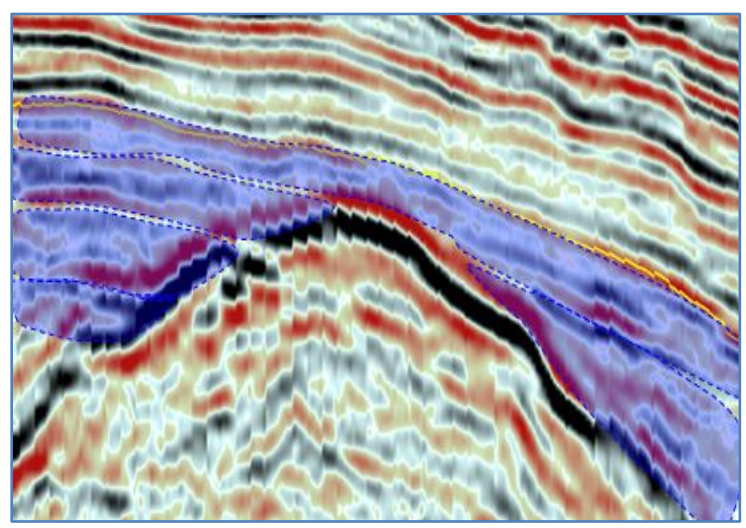

(b) seismic facies in a parallel source direction

Figure 4. Seismic facies characteristics of oil group II of the lower second member of Dongying Formation in Bohai L oilfield. 


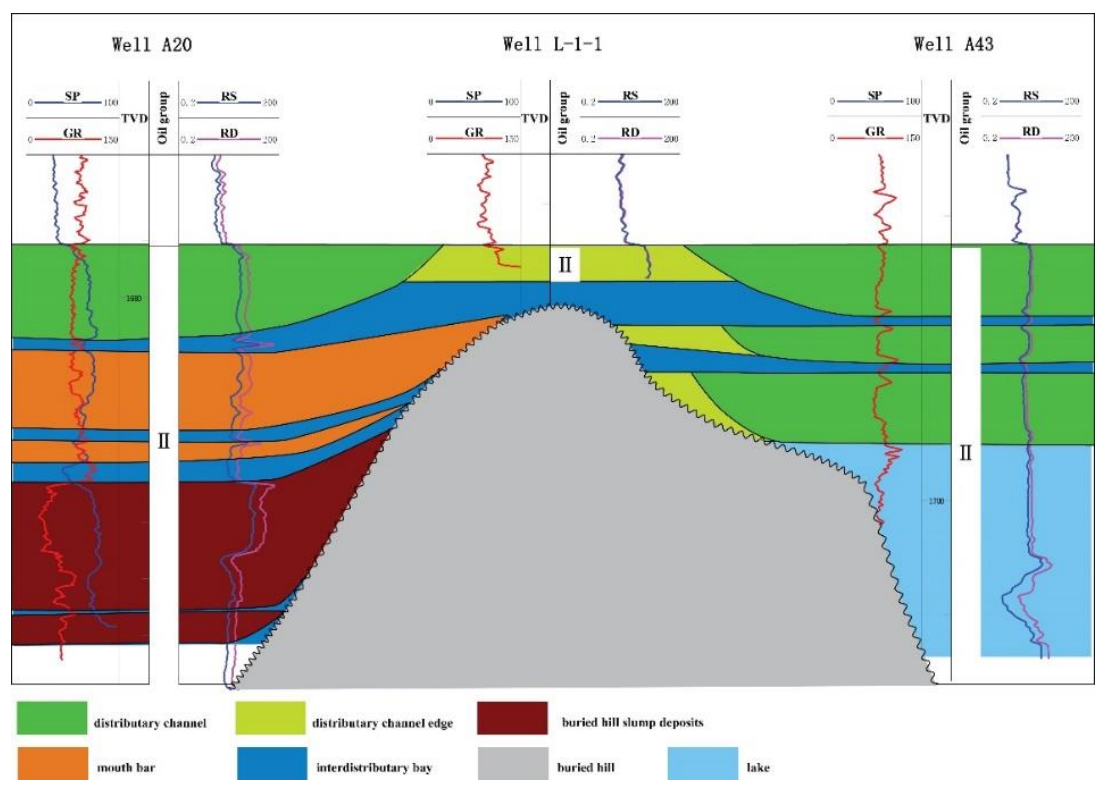

(a) sedimentary facies in a vertical source direction

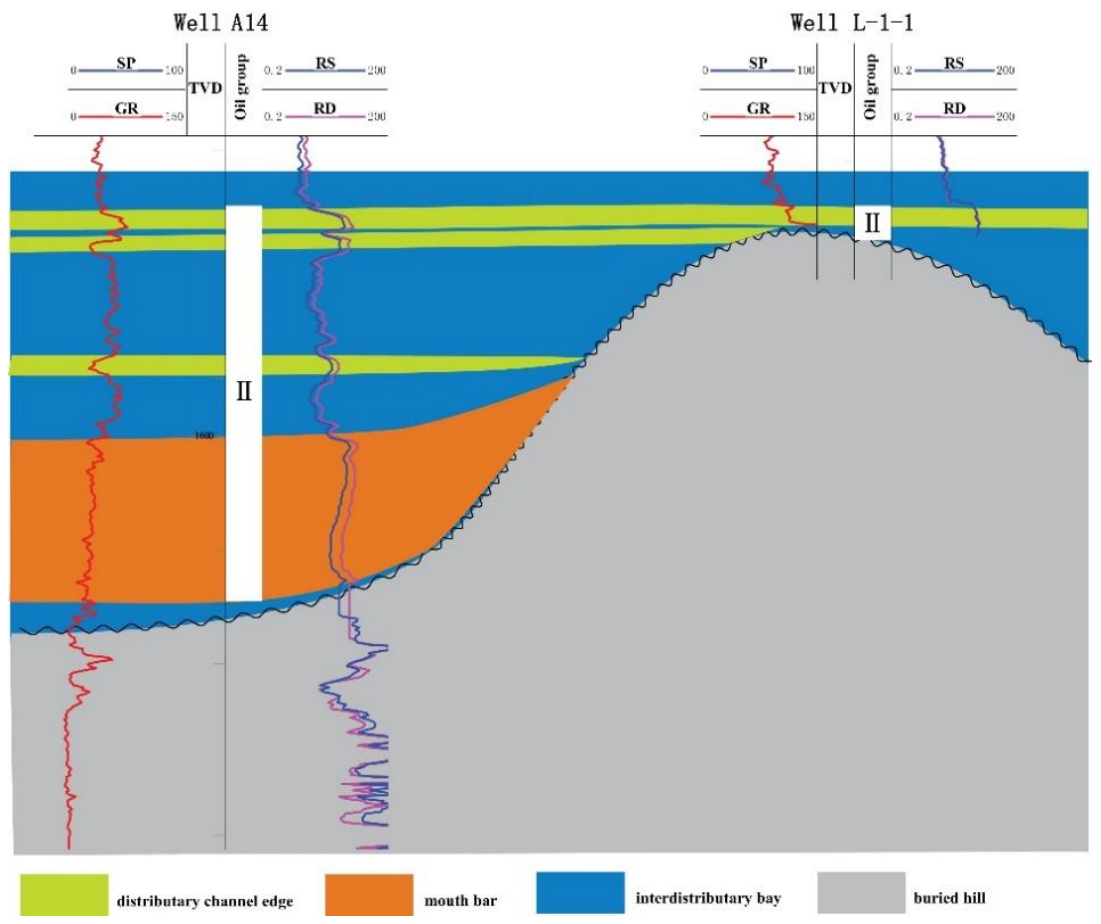

(b) sedimentary facies in a parallel source direction

Figure 5. Well section sedimentary facies characteristics of oil group II of the lower second member of Dongying Formation in Bohai L oilfield. Well locations are shown in Figure 1b.

\subsection{Sedimentary Distribution and Evolution}

Guided by the ascending cycle of regional base-level, the analyses of paleogeomorphology, seismic facies and well-section facies show that oil group II in the lower second member of Dongying Formation of the study area is a progressive braided river delta deposit under the background of lacustrine transgression, and that sedimentary distribution is affected by provenance, lake level and buried hill basement.

During the early stage of oil group II, although the lake level had a relatively wide range, the buried hill basement was exposed above the lake level locally and received no deposits. Meanwhile, due to a limited source supply, underwater distributary channel and sand sheet deposits were only deposited in the north and west of the study area and only 
lacustrine argillaceous deposits were deposited around the buried hill (Figure 6d). With the improvement of provenance supply capacity, underwater distributary channels began to develop along the palaeo-valleys, and crevasse splay deposits were locally developed. However, the overall sand sedimentation was still limited. Sheet sand deposits were developed in the area around the buried-hill outcrops and slump deposits were locally developed (Figure 6c). With the continuous strengthening of provenance supply and rise of lake level, areas of buried-hill outcrop were further reduced. The palaeo-valleys, though still acted as dominant deposition areas for distributary channels, had a weakened controlling effect on deposition because of sedimentation filling. Underwater distributary channels were preferably deposited in areas around the buried hill outcrops in parallel source direction (Figure 6b). With the further rise of the lake level, the buried hill basement was completely underwater, and therefore, deposits covered the whole region of the first small layer of the study area. Influenced by the basement landform, reservoirs were most developed along the both sides of the buried hill (Figure 6a).

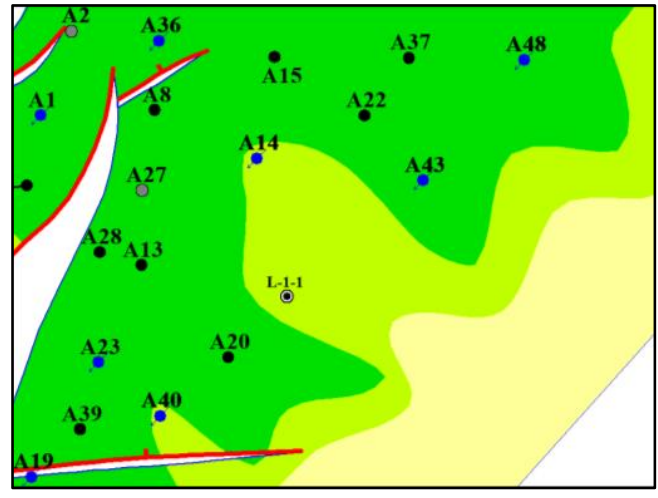

(a) sedimentary microfacies of the first small layer

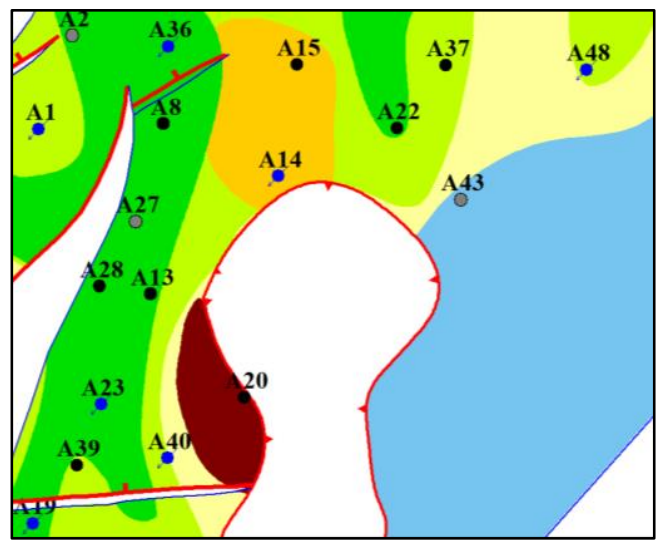

(c) sedimentary microfacies of the third small layer

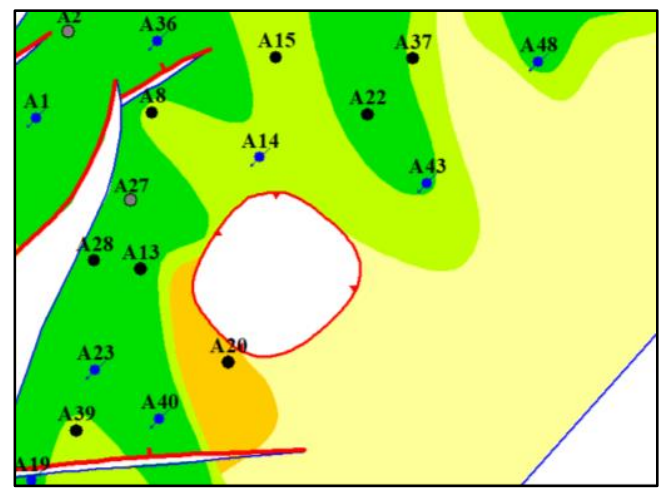

(b) sedimentary microfacies of the second small layer

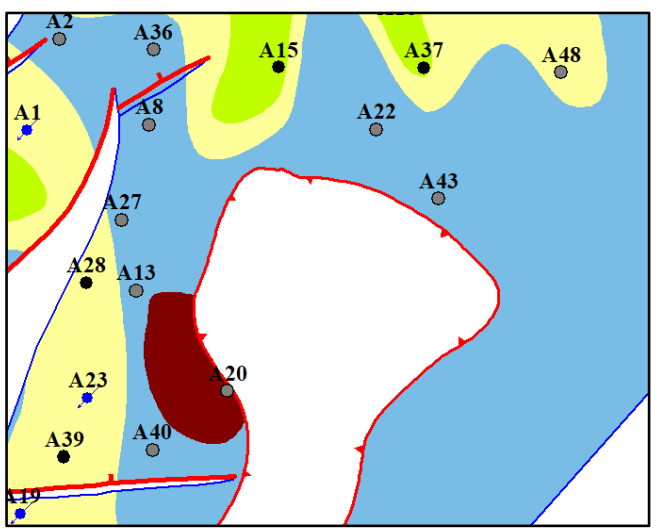

(d) sedimentary microfacies of the fourth small layer
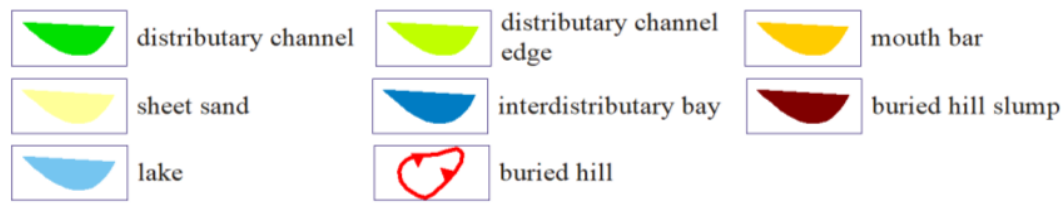

Figure 6. Sedimentary microfacies of each small layer of oil group II of the lower second member of Dongying Formation in Bohai L oilfield

\section{Application}

Based on the understanding of sedimentary distribution and evolution, the untapped reservoirs of oil group II in buried-hill draping zone are divided into four types. Type I is located in the west where underwater distributary channels dominate. The direction of the ancient valley is consistent with the provenance direction, and underwater distributary channel sand body is relatively developed with a relatively large thickness. Type II is located in the northwest where the dominant underwater distributary channel is developed. The scale of underwater distributary channel in each stage is smaller than that in the west, and the reservoir thickness is slightly smaller. Type III is located 
in the north. Reservoir thickness is smaller and physical property is also slightly worse than that of type II. It is mainly deposited with underwater distributary channel, underwater distributary channel edge and local crevasse splay. Type IV is located in the southeast, mainly composing sedimentary channel edge and sheet sand. The reservoir thickness is small and physical property is bad. Only reservoirs locally overlapped with underwater distributary channel in areas near the west have an improved physical property.

According to the detailed study of the reservoir, a three-step development strategy with four highly deviated wells was developed for the potential of the buried-hill draping zone (Figure 7). In the first step, Well X1 and X2 were deployed in type I reservoir. The drilling results of Well X1 and X2 verified the rationality of the research results. Well X1 and $\mathrm{X} 2$ drilled multi-stage channel sand bodies vertically (Figure 8). The reservoir thickness was large and the initial capacity could reach higher than $150 \mathrm{~m}^{3} / \mathrm{d}$. In the second step, a highly deviated Well X3 was deployed in type II reservoir. In the third step, a highly deviated Well X4 was deployed in type III reservoir. The reservoir and remaining oil conditions of Well X3 and X4 were the same as predicted before drilling. The initial capacity of Well X3 and Well $\mathrm{X} 4$ were both higher than $50 \mathrm{~m}^{3} / \mathrm{d}$.
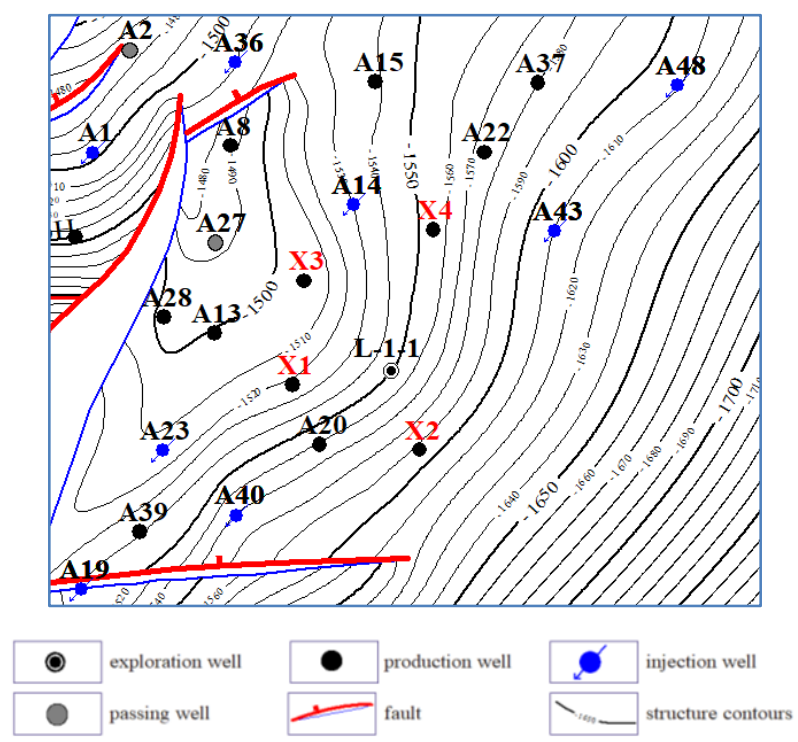

Figure 7. Well location design of the buried-hill draping zone of oil group II of the lower second member of Dongying Formation in Bohai L oilfield. The four new designed wells are marked in red.

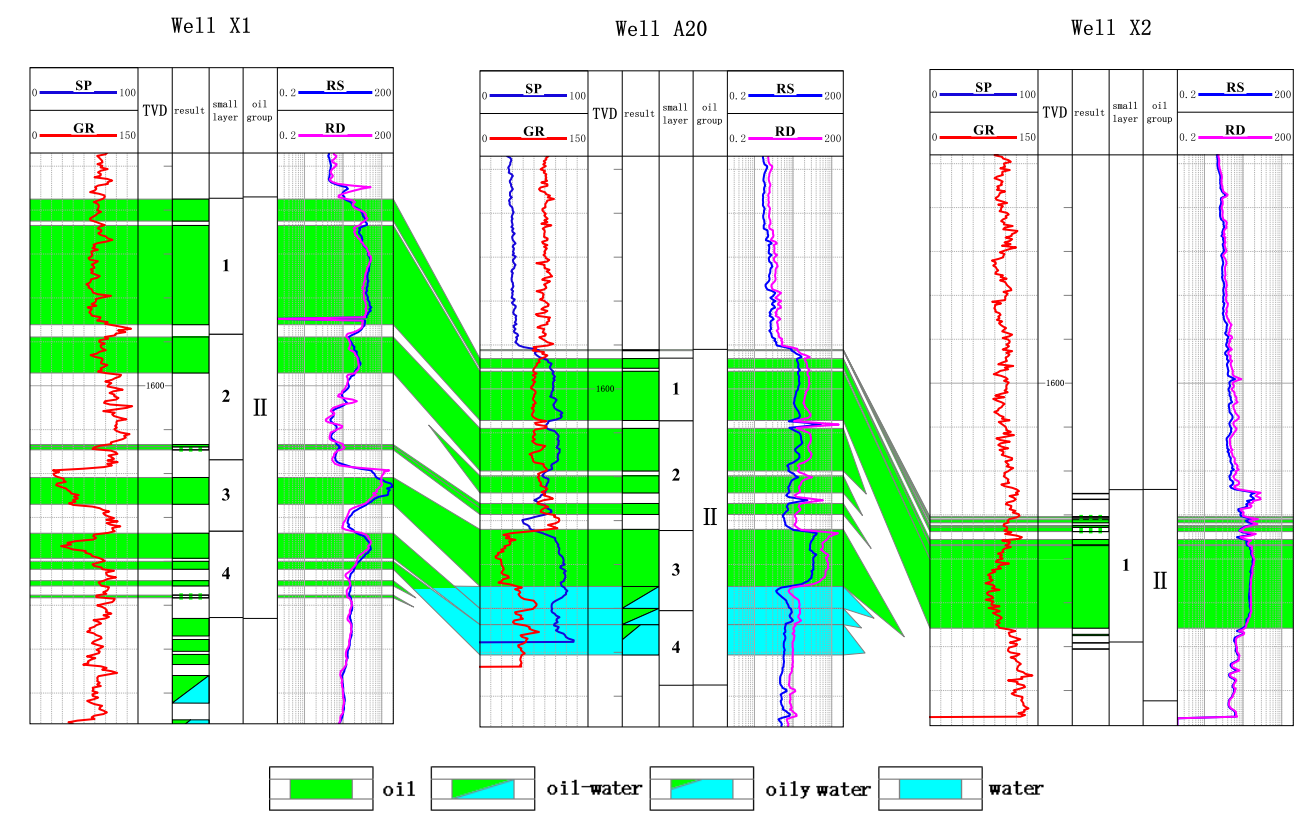

Figure 8. Comparisons between newly drilled wells (X1/X2) and old wells(A20) in the buried-hill draping zone 
Based on the deep study of the reservoirs in the buried-hill draping zone, four highly deviated wells were deployed to tap the remaining oil. The recovery factor is expected to be $8.6 \%$. The remaining oil tapping in the buried-hill draping zone has been revitalized. The problem that has been restricting the efficient development of L oilfield for many years is solved.

\section{Conclusion}

Oil group II of the lower second member of Dongying Formation of the study area is a progressive braided river delta deposit under the background of lacustrine transgression. The main sedimentary microfacies include underwater distributary channel, channel edge, mouth bar, sheet sand, interdistributary bay, etc.

Reservoir characteristics of the overlying strata in the buried-hill draping zone are controlled by paleogeomorphology, lake level change and provenance supply. Lake level change and provenance supply control the distribution range of reservoirs, while paleogeomorphology controls the distribution of predominant reservoirs.

The paleogeomorphology of oil group II of the lower second member of Dongying Formation of the study area is characterized by concave, slope and convex during the deposition period. The paleogeomorphology pattern controls the distribution of the predominant sedimentary reservoirs. Quality of the reservoirs in the buried-hill draping zone is better in the west than in the east and better in the south than in the north.

\section{References}

Cui, Y., Li, H. J., Fu, L. X., Xiao, F., Wang, H., Duan, R. M., Zhang, J. N., Feng, J. Y., Yang, Z. Y., \& Zhao, Z. J. (2018). Characteristics, main controlling factors and development model of Ordovician buried-hill reservoir in Beidagang structural belt, Qikou sag. Acta Petrolei Sinica, 39(11), 1241-1252.

Dong, G. Y., \& He, Y. B. (2016). Mechanism of sand body prediction in a continental rift basin by coupling paleogeomorphic elements under the control of base level. Petroleum Exploration and Development, 43(4), 529-539.

Dong, Y. X., Zhao, Z. J., Cao, Z. H., Wang, J. G., Gong, F. X., Wang, P. X., Wu, H. Y., Cao, R. N., \& Zou, G. (2015). Exploration potential and significance of Ordovician carbonate karst monadnock traps in Nanpu sag. Acta Petrolei Sinica, 6(6), 653-663.

Fu, L. X., Lou, D., Li, H. J., Qi, J. F., Feng, J. G., Guo, J. Y., Wu, X. S., \& Zhao, Y. G. (2016). Control effect of Indosinian-Yanshan movement on the formation of buried hill in Dagang exploration area. Acta Petrolei Sinica, 37(S2), 19-30.

Gao, Y., Jiang, Z. X., Li, J. J., Liu, S. Q., Wu, M. H., \& Wang, X. B. (2015). Restoration of paleogeomorphology and its controlling effect on deposition of beach-bar sand bodies: a case study of the fourth member of Shahejie Formation, Shubei area, Liaohe Western Sag. Petroleum Geology and Recovery Efficiency, 22(5), 40-46.

Guo, T., Li, H. Y., Shi, W. L., Wang, S. Q., \& Tu, X. (2015). Tectonic-sedimentary characteristics and favorable exploration targets in the Chengbei low uplift and neighboring regions in Bohai Sea area. Petroleum Geology and Recovery Efficiency, 22(2), 28-32.

Jin, F. M., Wang, X., Li, H. J., Wu, X. S., Fu, L. X., Lou, D., Zhang, J. N., \& Feng, J. Y. (2019). Formation of the primary petroleum reservoir in Wumaying inner buried-hill of Huanghua Depression, Bohai Bay Basin, China. Petroleum Exploration and Development, 46(3), 521-529.

Liu, X. W., Zhu, Y. F., Su, J., Wang, K., \& Zhang, B. T. (2014). The Characteristics and the controlling accumulation factors of buried hill reservoir in Hanilcatam, Tarim basin. Journal of Southwest Petroleum University (Science \& Technology Edition), 36(4), 37-46.

Luo, H. Z., Peng, J., Ye, Z., Xi, W. Y., \& Liu, Y. (2008). Hydrocarbon accumulation pattern and reservoir type analysis of Taizhou low bulge and its peripheral area in Subei basin. Special Oil and Gas Reservoirs, 15(2), 22-24.

Lv, Z. Y., Zhang, X. T., Bian, L. E., Wang, J., \& Wang, T. (2018). Exploration discoveries of elusive reservoirs using detailed paleogeomorphology reconstructions. Journal of Southwest Petroleum University (Science \& Technology Edition), 40(6), 12-22.

Ma, H. F. (2004). Analysis on oil-gas reservoir forming rule in Changdi buried hill drape structural belt. Petroleum Geology and Recovery Efficiency, 11(5), 33-35.

Qiao, Z. F., Li, G. R., Li, T., Wang, X., Yu, H. B., \& Deng, X. J. (2008). Sequence stratigraphic and their controls on carbonate reservoirs for the Triassic Jialingjiang Formation of the Luzhou Paleoghigh in Sichuan basin. Acta Sedimentologica Sinica, 26(1), 92-99. 
Ren, B. B., Qu, J. H., Wang, Z. S., Qian, H. T., \& Tang, Y. (2016). Hierarchical control function of the paleogeomorphology in Triassic period on sedimentaion in Mahu sag. Journal of Southwest Petroleum University (Science \& Technology Edition), 38(5), 81-89.

Shen, P. Y., Liu, Z., Liu, S. M., Ma, L. C., Sun, C., Li, Z. Y., Yang, X. G., \& Lu, C. J. (2018). Developing pattern and distribution features of biological limestone in the first Member of Shahejie formation in Changdi area, Zhanhua depression, Bohai Bay Basin, China. Acta Sedimentologica Sinica, 36(5), 995-1007.

Sun, W., Liu, S. G., Shi, H. X., Song, M. Y., Xu, C. H., He, J. J., \& Yong, Z. Q. (2008). Structural evolution and its control to hydrocarbon accumulation of Zhuanghai carbonate buried hills, Jiyang depression. Petroleum Geology and Recovery Efficiency, 15(3), 23-25.

Tong, K. J., Li, B., Dai, W. H., Zheng, H., Zhang, Z. N., Cheng, Q., Wang, J. L., \& Fang, N. (2017). Sparse well pattern and high-efficient development of metamorphic buried hills reservoirs in Bohai Sea area, China. Petroleum Exploration and Development, 44(4), 590-599.

Wang, Y. S., \& Li, J. Y. (2017). Characteristics and main controlling factors of layered reservoir in buried hill of carbonate rock in Pingfangwang oilfield, Jiyang depression. Journal of China University of Petroleum, 41(4), 27-35.

Yan, H. J., He, D. B., Xu, W. Z., Wang, G. T., Ji, G., Tian, G. Q., Huo, J. Z., Ma, H. H., Huang, H. J., \& Xie, T. Z. (2016). Paleotopography restoration method and its controlling effect on fluid distribution: a case study of the gas reservoir evaluation stage in Gaoqiao, Ordos basin. Acta Petrolei Sinica, 37(12), 1483-1494.

Zhang, Q. P., Liu, Z. B., Liao, X. W., Li, H. Y., Liu, Y. J., \& Zheng, B. (2020). Stratigraphy and deposition model of Palaeogene Dongying braided-river delta sandstones, L Field, Bohai Bay Basin, offshore eastern China. Earth Science Research, 9(1), 1-13. https://doi.org/10.5539/esr.v9n1p1

Zhao, N., Deng, H. W., \& Wang, X. L. (2010). Beach-bar deposition and petrophysical properties around buried hill of the second member of Paleogene Shahejie Formation in Zhanhua sag, Jiyang depression. Journal of Palaeogeography, 12(1), 57-68.

Zhao, Y. G., Wang, D. X., Feng, Q. H., Zhang, D. L., Wang, S. F., Feng, Y. J., Fu, X. Y., \& Nan, X. X. (2017). Review on paleogeomorphology reconstruction methods in oil and gas fields. Journal of Earth Sciences and Environment, 39(4), 516-529.

\section{Copyrights}

Copyright for this article is retained by the author(s), with first publication rights granted to the journal.

This is an open-access article distributed under the terms and conditions of the Creative Commons Attribution license (http://creativecommons.org/licenses/by/4.0/). 